\title{
THE LAND SURFACE TEMPERATURE EVOLUTION (LST) USING LANDSAT SCENES. CASE STUDY: THE INDUSTRIAL PLATFORM SĂVINEŞTI
}

\author{
Cosmina-Daniela URSU ${ }^{1}$
}

DOI: 10.21163/GT_2019.142.12

\begin{abstract}
:
During the communism, the accent of development was put mainly on industry. This is also the case of The Industrial Platform Săvineşti, from Neamţ county, which assured two major productions: textile fibers and chemical fertilizers. After the fall of the regime, the platform was divised and some of the new owners have sold all the equipments, have demolished the buildings, leaving the place barren. In the present, only a few of the old factories still work, and new stakeholders started their businesses. The study aims to show how the land surface temperature (LST) evolved in association with the events that followed from the flowering period of the factory. Three summer months from different years (1991, 2008 and 2018) where taken into consideration and LST was calculated based on Landsat scenes from missions 5-TM and 8-OLI. In order to make the whole process faster, two models were constructed using ArcMap extesion Model Builder. Besides the land surface temperature, there were calculated another two indices: Normalized Difference Vegetation Index (NDVI) and Normalized Difference Moisture Index (NDMI), which offer additional arguments to the changes that took place on the platform. The purpose of the study is to show how land surface temperature changes depending on the use of the territory, thus the importance of remote sensing being emphasised.
\end{abstract}

Key-words: Land cover changes, Romanian industry, Model Builder

\section{INTRODUCTION}

In the communism era, the industry was the economic field which was predominantly developped. The industrial Platform from Săvineşti began to function in 1959, being described in literature of that time as "the first and most important yarn factory from the country which produced technical yarns for various uses (textile fibers, special yarns, mechanical sieves, industrial fishing gear, belts and tapes). Only the textile fibers production equals the annual wool production of over 4 million sheep" (Maria Mihail, 1977, p. 201-202). The Platform covered an area of approximately 185 ha and it was composed of: Synthetic yarn and fiber plant, Azochim Chemical Fertilizer Plant and a research institute. After the fall of the communist regime, in 1990, the platform was divised in independent structures. Some of them (Yarn Factory) were taken by foreign companies, others like Azochim was bought by Romanian business men. Numerous machines were sold, the old halls were demolished and massive layoffs were made. According to some interviews taken by the press from former workers, in 2004, there were only 350 employees, as opposed to 1990 , when 8000 people worked in the yarn factory ${ }^{1}$. Figures number $\mathbf{1}$ and $\mathbf{2}$ show the differences before the fall of the communism and after.

${ }^{1}$ Babeş Bolyai University, Faculty of Geography, 400006, Cluj-Napoca, Romania, ursucosmina@yahoo.com 


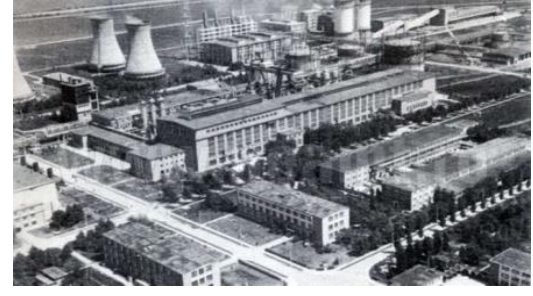

Fig. 1. The Factory of synthetic fibers Săvinești-1959²

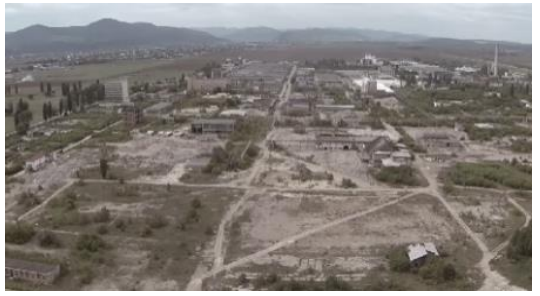

Fig. 2. The Industrial Platform - 2015 (image taken with the drone ${ }^{3}$ )

Remote sensing has prooved its usefullness ever since the beginnings. Landsat is one of the oldest missions which has the advantage of releasing many images free of charge for any type of users. Landsat scenes are often used for various types of analysis: tracking forest changes (Furtuna et al., 2016, Furtuna, 2017), detection of areas affected by storms (Furtuna et al., 2018;), detection of the old scattered windthrows (Haidu et al., 2019).

For the climate domain, the thermal sensor from Landsat allow the calculation of Land Surface Temperature (LST) which is an index that shows the ground temperature recorded by the satellite thermal sensor (Rajeshwari and Mani, 2014). This should not be confused with the air temperature, the two having different values, but being well correlated. In most scientific articles (Zhang \& Sun, 2008; Kim, 2009; Choudhury \& Das Arijit Das, 2019) LST is used in the determination of urban heat islands (Urban Heat Islands-UHI). The studies mainly analyze urban spaces, less industrial areas, although "the presence of impervious surfaces such as buildings, roads, industrial farms increase the absorption of short radiations and diminish the loss of energy due to the emission of long wave radiation" (Oke, 1976, quoted by Choudhury \& Das Arijit Das, 2019). In a case study conducted for a Chinese mining city (Rao et al., 2018) LST correlated with the type of industrial activity from each mining area. The results show that LST differs according to the industrial activity practiced. Other authors have described the link between land use and LST (Voogt \& Oke, 2003; Gage \& Cooper, 2017), especially analyzing the consequences of the urbanization process in increasing LST (Owen et al., 1998; Small, 2006; Guo et al., 2012).

The study aims to analyze the evolution of land surface temperature on the Platform, using Landsat scenes. The hypothese is the following: the temperature is influenced by the cessation of industrial activity in certain areas of the platform. Moreover, in order to sustain the results of LST, Normalized Difference Vegetation Index (NDVI) and Normalized Difference Moisture Index (NDMI) were added. The analys is performed using ArcMap 10.6. For making the process faster, two models were constructed using Model Builder. After every calculation, the results were compared between years, in order to emphasize the differences.

\section{STUDY AREA AND DATA}

The Industrial Platform is located in the central area of the Săvineşti Commune, which is part of Neamţ County (Fig. 3). For modeling land surface temperature, Landsat scenes from Landsat Collection 1-Level 1 were used, downloaded from USGS Earth Explorer. For each image additional criteria (the cloud cover under $10 \%$ and the time of the day) were specified. The three images were chosen in the summer in order to avoid great cloud cover, mist, snow and other natural phenomena.Details about each image could be found in Tab.1 

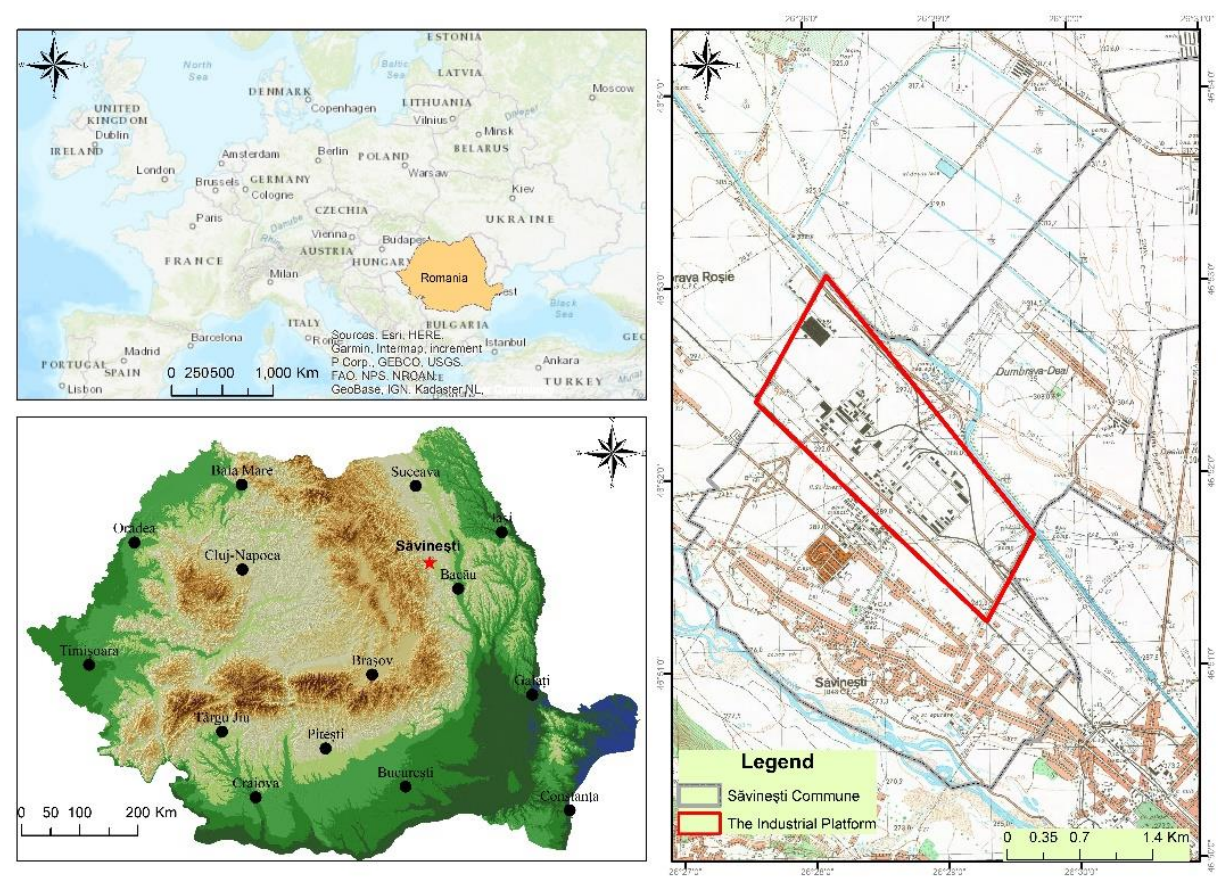

Fig. 3. The localization in the territory of Săvineşti commune.

Tabel 1.

Details about data.

\begin{tabular}{|c|c|c|c|c|}
\hline No. & Path & Row & Date & Satellite \\
\hline 1 & 183 & 27 & 8.08 .1991 & 5 \\
\hline 2 & 183 & 27 & 22.08 .2008 & 5 \\
\hline 3 & 183 & 27 & 18.08 .2018 & 8 \\
\hline
\end{tabular}

\section{METHODOLOGY}

Before use, the images were preprocessed using ERDAS version 2014. Operation like Histogram equalization, Haze and noise reduction were performed in order to improve the quality of the image.

Arc Map 10.6.1 was used for land surface temperature estimation. From Landsat 5TM, the band 6 (10.40-12.50 micrometers) was used, and from Landsat 8-OLI, band 10 Thermal Infrared (10.60 - 11.19 micrometers).

The first step was to reproject the bands of each image from their default projection system (WGS 1984) to Stereo 1970, the projection system used in the country level. The next step was cutting the images after the limit of the case study. 
The area includes not only the territory of the platform, but also the surroundings in order to see the temperature differences.

\subsection{LST using Landsat 5-TM}

The methodology is different based on Landsat mission. Thus, for Landsat 5 the first parameter calculated was the spectral radiance, when the pixells are converted from digital numbers (DN) to units of absolute radiance, using the following formula:

$$
L_{\lambda}=\left(\frac{L M A X_{\lambda}-L M I N_{\lambda}}{Q C A L M A X-Q C A L M I N}\right) \cdot(\mathrm{QCAL}-\mathrm{QCALMIN})+L M I N_{\lambda}
$$

where:

$\mathrm{L} \lambda=$ Spectral Radiance at the sensor's aperture in watts/(meter squared $*$ ster $* \mu \mathrm{m})$

$\mathrm{QCAL}=$ the quantized calibrated pixel value in DN

$\operatorname{LMIN} \lambda=$ the spectral radiance that is scaled to QCALMIN in watts/(meter squared * ster $* \mu \mathrm{m})$

LMAX $\lambda=$ the spectral radiance that is scaled to QCALMAX in watts/(meter squared * ster $* \mu \mathrm{m})$ in $\mathrm{DN}$

QCALMIN = the minimum quantized calibrated pixel value (corresponding to LMIN $\lambda$ )

QCALMAX = the maximum quantized calibrated pixel value (corresponding to LMAX $\lambda$ ) in $\mathrm{DN}=255$

The next step is calculating the effective satellite visualized temperature of the Earthatmosphere visual system, which in the case of Landsat 5-7 images corresponds to the land surface temperature (LST) (Chander and Markham, 2003). By adding -273.15, the conversion from Kelvin to Celsius degrees is made. The formula is:

$$
T=\frac{K 2}{\ln \left(\frac{K 1}{L_{\lambda}}+1\right)}-273.15
$$

Where:

$\mathrm{T}=$ Effective at-satellite temperature in Kelvin

$\mathrm{K} 2$ = Calibration constant 2 from metadata fille

$\mathrm{K} 1$ = Calibration constant 1 from metadata fille

$\mathrm{L}=$ Spectral radiance in watts/(meter squared $*$ ster* $\mu \mathrm{m})$

\subsection{LST using Landsat 8}

In the case of Landsat 8 scenes, the methodology has a higher degree of complexity. The first step is the conversion of the digital numbers into radiance units, using the next ecuation (LANDSAT 8 (L8) data users handbook, 2019):

$$
\mathrm{L} \lambda=\mathrm{ML} * \mathrm{Qcal}+\mathrm{AL}
$$

Where:

$\mathrm{L} \lambda=$ Spectral radiance $(\mathrm{W} /(\mathrm{m} 2 * \mathrm{sr} * \mu \mathrm{m}))$

$\mathrm{ML}=$ the band-specific multiplicative rescaling factor (RADIANCE_MULT_BAND_n from metadata fille). 
$\mathrm{AL}=$ the band-specific additive rescaling factor (RADIANCE_ADD_BAND_n din metadate). Qcal = the Band 10 image.

The second step supposes the conversion of spectral radiance to the the actual temperature visualized by the satellite (LANDSAT 8 (L8) data users handbook, 2019):

$$
T=\frac{K 2}{\ln \left(\frac{K 1}{L_{\lambda}}+1\right)}
$$

Where:

$\mathrm{T}=$ Effective at-satellite temperature in Kelvin

$\mathrm{K} 2$ = Calibration constant 2 (K2_CONSTANT_BAND_n from metadata fille)

$\mathrm{K} 1=$ Calibration constant 1 (K1_CONSTANT_BAND_n from metadata fille)

$\mathrm{L}_{\lambda}=$ Spectral radiance in watts/ (Watts $\left./\left(\mathrm{m}^{2} * \mathrm{sr} * \mu \mathrm{m}\right)\right)$

Next, NDVI has to be calculated in order to find out the proportion of vegetation $(P v)$ :

$$
N D V I=N I R-R / N I R+R
$$

Where:

NDVI= Normalized Difference Vegetation Index

$\mathrm{NIR}=$ Near infrared band

$\mathrm{R}=$ Red band

The proportion of vegetation $(P v)$ could be calculated using the following formula (Sobrino et al., 2004):

$$
P v=(N D V I-N D V I \min / N D V I \max -N D V I \min )^{2}
$$

After this, the surface emissivity can be derived (Sobrino et al., 2004):

$\mathrm{e}=0.004 * \mathrm{Pv}+0.986$

All this steps have as a result the final formula which gives the Land Surface Temperature (Avdan and Jovanovska, 2016):

$$
L S T=B T / 1+w *(B T / p) * \operatorname{Ln}(e))
$$

Where:

BT - Effective at-satellite temperature

$\mathrm{W}$ - radiation wavelength emitted (band 10)

e - surface emissivity

$\mathrm{p}=14380$

\subsection{Model Builder}

All this calculations were implemented using Raster Calculator from Arc Toolbox (Fig. 5). 


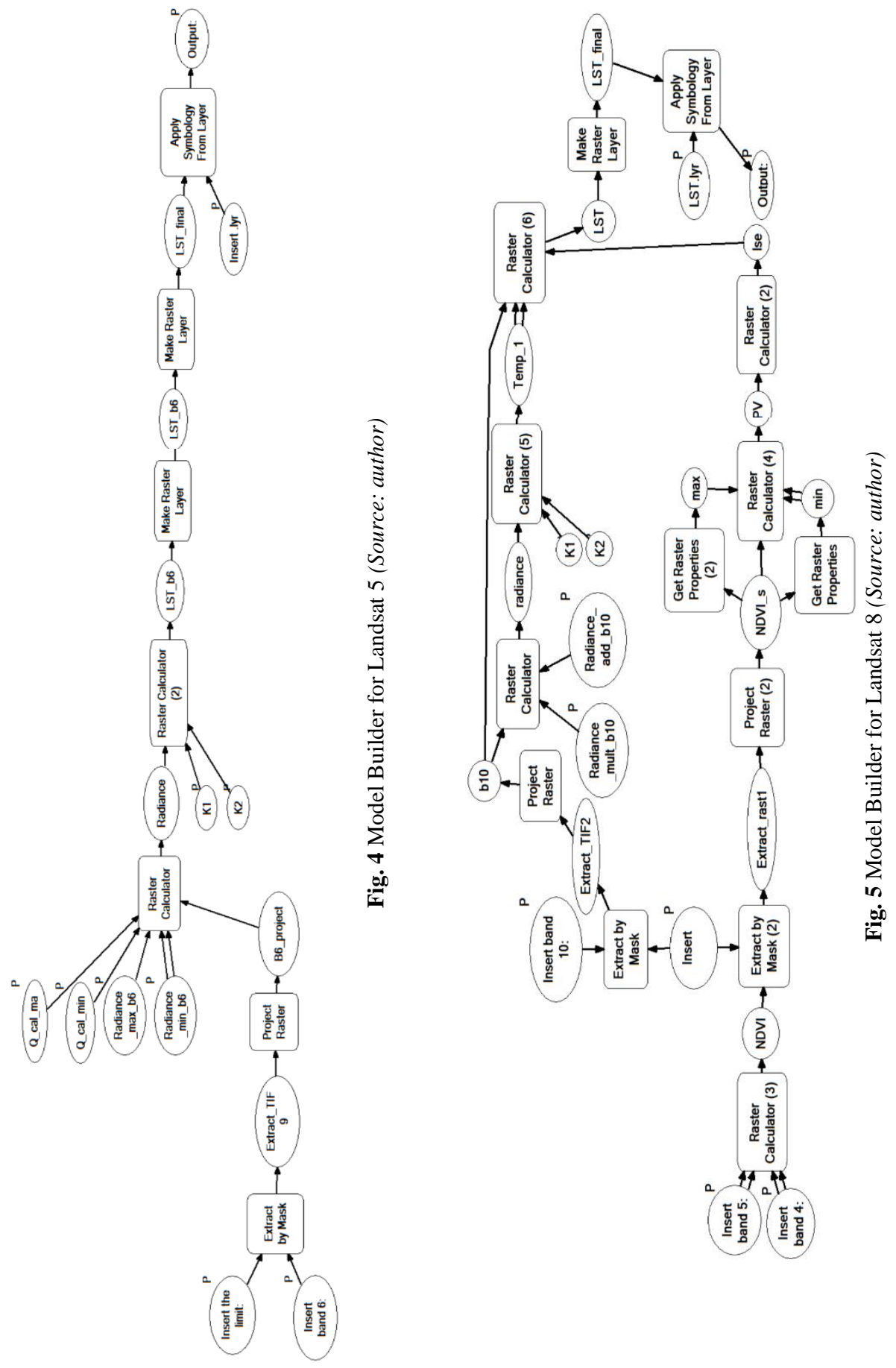


(ArcMap 10.6). But due to the fact that there might be mistakes in writing the formulas (like misplacing a space or forgetting a digit) if the process must be repeated for many Landsat scenes, automatic models were constructed with Model Builder from ArcMap 10.6 soft.

For Landsat 5, the model (Fig. 4) was constructed of six functions: Extract by mask (which cuts the study area from the larger scene), Project Raster (converts the scene into the national projection system), Raster Calculator (where the user has to introduce the parameters written in the metadata fille for the first formula (1), and then for the second one (2), Make Raster Layer and Apply Symbology from Layer are used to assign a specific legend for the result. The model calculates LST in just seconds and represent it with the colour ramp choosen by the user.

Given the fact that LST using Landsat 8 requires more operations than Landsat 5, an automatic model is more than needed. For this one (Fig. 5), its complexity reside in larger number of functions which have to be applied: Extract by Mask and Project Raster (have the same function as for Landsat 5 model), Raster Calculator (is used to calculate NDVI and other formulas as well- 3-7), Get Properties (is used to select the minimum and maximum value of NDVI), Make Raster Layer and Apply Symbology from Layer (are used to establish the colour ramp for the result).

\subsection{NDVI and NDMI calculation}

For NDVI retrieval, bands 3 and 4 were used for Landsat 5 and bands 4 and 5 for Landsat 8 scenes (see the formula above).

Normalized Difference Moisture Index (NDMI) was calculated using bands 4 and 5 for Landsat 5 and bands 5 and 6 for Landsat 8 scenes. The formula is:

$$
N D M I=N I R-I R / N I R+I R
$$

Where: NIR- Near infrared band; IR- infrared band.

\section{RESULTS AND DISCUSSIONS}

After applying the formulas, the Land Surface Temperature was retrieved for the three moments taken into account (Fig. 6).

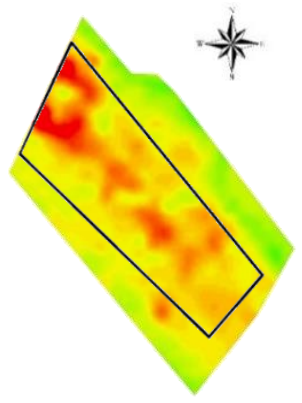

a. 8.08 .1989

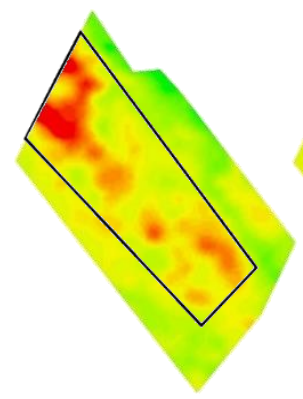

b. 22.08 .2008



c. 18.08 .2018

Fig. 6. Land Surface Temperature. 
At the first look, the west area had high temperatures, no matter the year of the image. This can be explained by the fact that in that area were located the factories that lasted until today and in that area, other companies have installed after the buildings were left. The central area of the platform suffered severe changes. The temperature went down from 1989 till 2018 as a result of changing the land use. After the existing buildings were destroyed, the soil recovered in time and vegetation started to reclaim its territory. This statement can be sustained by the Google Earth images (Fig. 7) which show the evolution of the area.

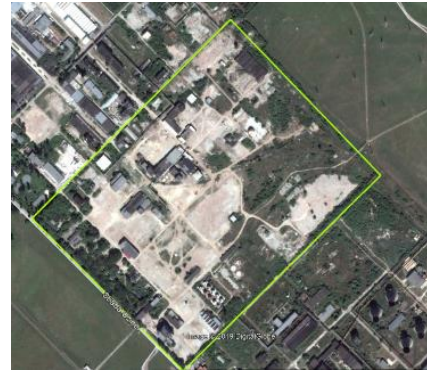

8.06.2011

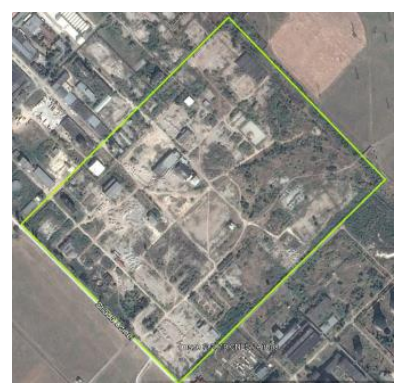

14.09.2014

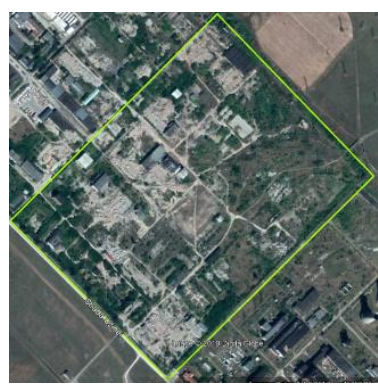

14.09.2017

Fig. 7. Evolution of the central area (Source: GoogleEarth).

The east area had fluctuations over the time because there is located Azochim Chemical Fertilizer Plant, which functioned with interruptions. Another observation is focussing on the peripheral areas of the Platform. As it can be remarked, the temperatures on the industrial site are higher that the ones from the surrounding area, like a heat island in the middle of agricultural land. In order to notice better the differences between the three moments, the results have been transformed by lowering opperations. Thus, the results show that the differences between the 2018-2008 are higher than the ones from 2018-1991 because most changes had happened after 2008, as we can see in Fig. 8. In both cases, in the south-east and west of the platform were the major changes, due to the interruption of industrial activity in some periods.

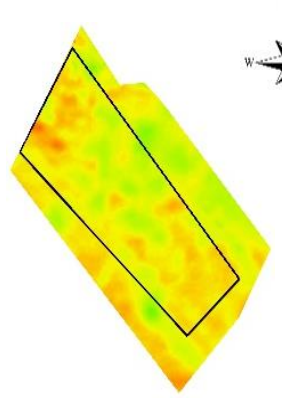

Fig. 8.a. 2018 - 1991

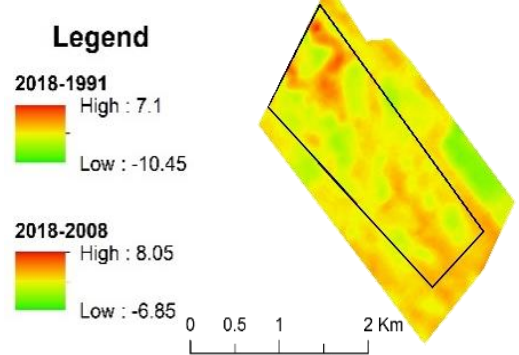

Fig. 8.b. $2018-2008$

Further, NDVI (Fig. 9) shows the reduction of the built spaces, followed by the appearance of the spontaneous vegetation on the place of the former halls, especially in the central area. The lack of vegetation in the western part is equivalent to the preservation of buildings where industrial activities are still practiced. 


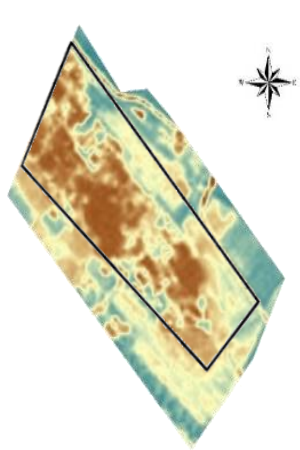

a. 8.08 .1991

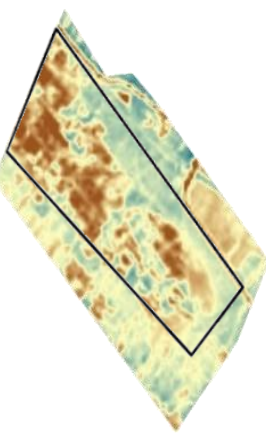

b. 22.08 .2008



c. 18.08 .2018

Fig. 9. (a,b,c) NDVI.

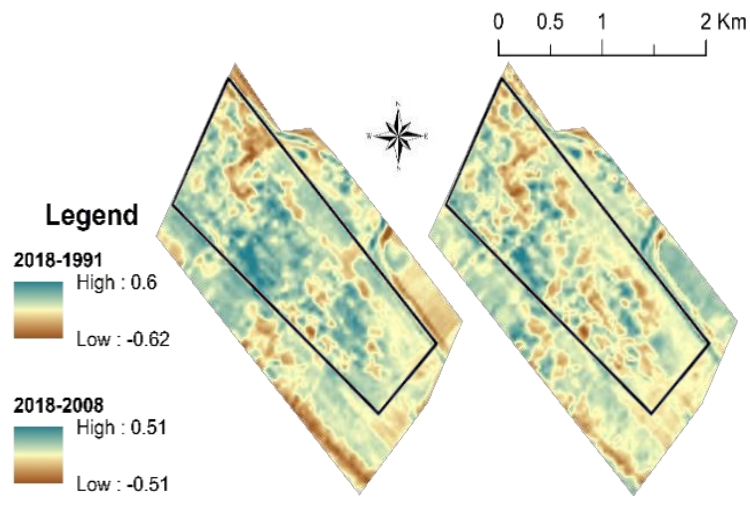

Fig. 10a. 2018 - 1991

Fig. 10b. 2018 - 2008

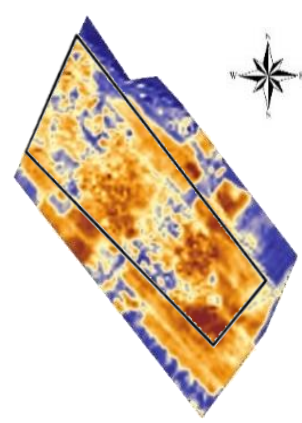

a. 8.08 .1991

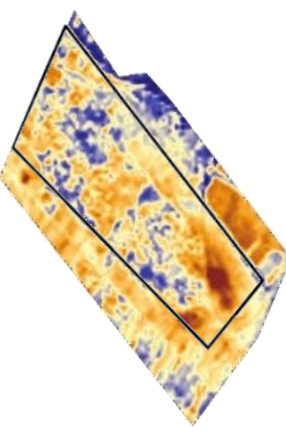

b. 22.08 .2008

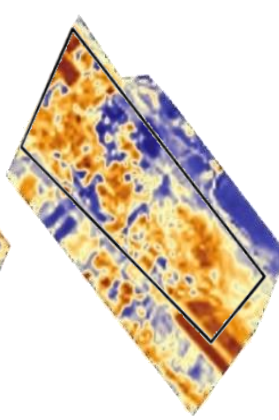

c. 18.08 .2018

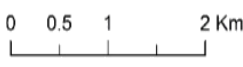

\section{Legend}

High : 0.39

Low : -0.26

Fig. $11(\mathbf{a}, \mathbf{b}, \mathbf{c})$ NDMI 


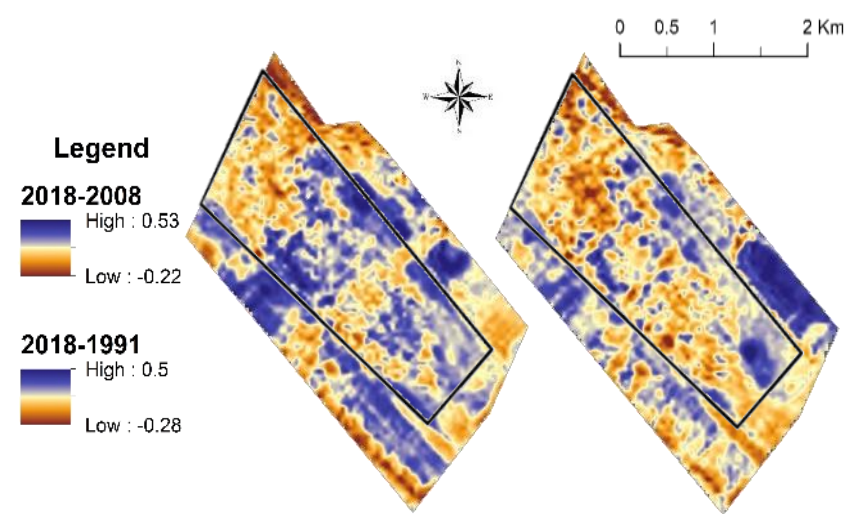

Fig. 12a. 2018-1991

Fig. 12b. 2018-2008

The legends of the two periods (Fig. 10) show that the differences were bigger for 2018-1991 than for 2018-2008. This is the result of the land use changes that occured after the demolition of some buildings. As it is represented in fig. 8a., changes took place in the center of the industrial platform.

Another index correlated with NDVI is NDMI (Fig. 11) which is used to capture the differences between humidity for the study area. In 1989 it is observed that the humidity is lowered especially in the central and eastern part of the platform, and that in 2018 it will increase, those surfaces being fragmented with positive values of humidity, which indicates the lands that have been left bare after the demolition of the industrial halls.

The differences between 2018-1991 and 2018-2008 are represented in Fig. 12 a,b. In this case, the values from the interval 2018-2008 are greater that the other interval. This can be correlated with the differences of NDVI: a thicker vegetation retains moisture better and longer than a bare ground.

\section{CONCLUSIONS}

For Săvinești Industrial Platform, the LST index proves to be a useful tool in observing the involution of the industrial activity. The similar study conducted for a Chinese mining town (Rao et al., 2018) shows that LST is influenced by the type of industrial activity practiced in various areas. And in the case of the platform too, LST shows how the industrial site have evolved, based on owners decisions.

In the three moments (1991, 2008 and 2018) we notice major differences in LST, especially during the summer. It can be deduced that the soil temperature decreases with the decrease of the industrial activity. The area in the western part of the area that remains constant with the highest temperatures is the area where industrial activities are still taking place. The central area is the one which suffered most changes, passing from built land to demolition of the constructions, bare ground and then spontaneous vegetation. The southeast area has various temperatures that coincide with the moments of activity and inactivity.

In conclusion, the evolution of an industrial platform can be demonstrated through satellite imagery. Demolition of buildings, restriction of industrial activity can be observed both visually and by calculating satellite indices such as LST, NDVI, NDMI. 
They provide information on how to use the land, on the ground temperature, which can be indicators of the evolution or involution of some industrial areas. Of course, this information obtained from the processing of satellite images must be correlated with the events that have occurred over time, so knowing the history of the study area is a way to confirm or deny the results of the satellite indices.

\section{R E F E R E N C E S}

Avdan, U. \& Jovanovska, G., (2016), Algorithm for Automated Mapping of Land Surface Temperature Using LANDSAT 8 Satellite Data, Journal of Sensors, 2016 (2), 1-8

Chander, G. \& Markham, B., (2003), Revised Landsat-5 TM Radiometric Calibration Procedures and Postcalibration Dynamic Ranges, IEEE Transactions on Geoscience and Remote Sensing, 41(11), 2764-2677

Choudhury D. \& Das Arijit Das, K., (2019), Assessment of land use land cover changes and its impact on variations of land surface temperature in Asansol-Durgapur Development Region, The Egyptian Journal of Remote Sensing and Space Science, 22, (2), 203-218

Department of the Interior U.S. Geological Survey, (2019), LANDSAT 8 (L8) Data Users Handbook, EROS Sioux Falls, South Dakota, https://prd-wret.s3-us-west2.amazonaws.com/assets/palladium/production/atoms/files/LSDS1574_L8_Data_Users_Handbo ok_v4.pdf

Fils, S. C. N., Mimba, M. E., Dzana, J.G., Etouna, J., Mounoumeck, P. V., Hakdaoui, M. (2018), TM/ETM+/LDCM Images for Studying Land Surface Temperature (LST) Interplay with Impervious Surfaces Changes over Time Within the Douala Metropolis, Cameroon, Journal of the Indian Society of Remote Sensing, 46(1), 131-143

Furtuna, P., Haidu, I., Alexe, M. \& Holobaca, I. (2016) Change Detection in the Cluj forest district, using remote sensing and GIS application, Environmental Engineering and Management Journal, 15(6), 1361-1368.

Furtuna, P. (2017) Temporal and spatial variation of forest coverage in Apuseni Natural Park, 20002014 period, Geographia Technica, 12(1), 46-56. DOI: 10.21163/GT_2017.121.05

Furtuna P., Haidu, I., Maier N. (2018) Synoptic Processes Generating Windthrow. A Case Study for Apuseni Mountains (Romania). Geographia Technica, 13(2), 52-61, DOI:10.21163/GT_2018.132.04

Gage, E., Cooper, D.J., (2017), Urban forest structure and land cover composition effects on land surface temperature in a semi-arid suburban area, Urban forestry and urban Greening 28, 28-35

Guo, Z., Wanga, S.D., Chengc, M.M., Shub, Y. (2012), Assess the effect of different degrees of urbanization on land surface temperature using remote sensing images, Procedia Environmental Sciences $13,935-942$

Haidu, I., Furtuna, P., Lebaut, S. (2019) Detection of old scattered windthrow using low cost resources. The case of Storm Xynthia in the Vosges Mountains, 28 February 2010, Open Geosciences, 11(1), 492-504, https://doi.org/10.1515/geo-2019-0040

Maria Mihail, (1977), Romania Economic Geography, Part 1, Cluj-Napoca

Owen, T.W., Carlson, T.N., Gillies, R.R. (1998), An assessment of satellite remotely-sensed land cover parameters in quantitatively describing the climatic effect of urbanization, International Journal of Remote Sensing, 19(9), 1663-1681

Rajeshwari A. \& Mani, N. (2014) Estimation of Land Surface Temperature of Dindigul district using Landsat 8 data, International Journal of Research in Engineering and Technology, 3(5), 122126 
Rao, Y., Xua, Y., Zhanga, J., Guob, Y., Fua, M., (2018) Does subclassified industrial land have a characteristic impact on land surface temperatures? Evidence for and implications of coal and steel processing industries in a Chinese mining city, Ecological Indicators, 89, 22-34

Small, C., (2006), Comparative analysis of urban reflectance and surface temperature, Remote Sensing of Environment, 104(2), 168-189

Sobrino, J.A., Jiménez-Muñoz, J.C., Paolini L. (2004) Land surface temperature retrieval from Landsat TM 5, Remote Sensing of Environment, 90(4), 434-440

Voogt, J.A., Oke T.R. (2003), Thermal remote sensing of urban climate, Remote Sensing of Environment, 86 (2003), 370-384

Zhang, Y., Sun, L., (2019), Spatial-temporal impacts of urban land use land cover on land surface temperature: Case studies of two Canadian urban areas, International Journal of Applied Earth Observations and Geoinformation, 75,171-181

${ }^{1}$ https://stirileprotv.ro/stiri/actualitate/un-combinat-unic-in-europa-distrus-de-investitorii-straini-panaacum-2-zile-era-rentabil-si-acum-nu-mai-e.html- online article [Accessed Mars 2019]

${ }^{2} \mathrm{https}$ //adevarul.ro/locale/piatra-neamt/cum-s-a-prabusit-platforma-chimica-savinesti-colosulindustrial-lucrau-10000-nemteni-1_535f3b930d133766a82f7760/index.html [Accessed Mars 2019]

${ }^{3}$ https://www.youtube.com/watch?v=byHh-JIMZiU [Accessed Mars 2019]. 